\title{
Radiation processed ethylene vinyl acetate-multiple walled carbon nanotube nano-composites: Effect of MWNT addition on the gel content and crosslinking density
}

\author{
K. A. Dubey, Y. K. Bhardwaj*, C. V. Chaudhari, Virendra Kumar, N. K. Goel, S. Sabharwal \\ Radiation Technology Development Section Bhabha Atomic Research Centre, Trombay Mumbai-400 085, India
}

Received 2 March 2009; accepted in revised form 24 May 2009

\begin{abstract}
Different compositions of ethylene vinyl acetate (EVA)/multiple walled carbon nanotube (MWNT) nano-composites were prepared by melt mixing and subjected to different doses of gamma radiation. The efficiency of radiation vulcanization was analyzed by sol-gel analysis, Charlesby-Pinner parameter estimation and crosslinking density measurements. Gamma radiation induced crosslinking was found to increase with MWNT fraction in EVA-MWNT nanocomposites ( $p_{0} / q_{0}$ in the range: 1.15-0.98). These results ruled out the possibility of a significant neutralization of single ionization spurs by MWNT addition. The incorporation of MWNT also resulted in increased hardness and higher density of the nano-composite matrix. The efficiency of multifunctional acrylates as crosslinking aid in the radiation-induced vulcanization of EVA-MWNT nano-composites was also investigated. The results established lower efficiency of methacrylates than of acrylates in the radiation vulcanization process.
\end{abstract}

Keywords: nanocomposites, gamma-radiation, EVA, MWNT, crosslinking

\section{Introduction}

Elastomeric materials are usually reinforced by carbon black, silica and other microscopic fillers for improving/enhancing/achieving the desired properties [1-3]. Composites filled with nanofillers such as metallic nanoparticles and carbon nanotubes have been envisaged to have superior physical and mechanical properties compared to the conventional fiber or particle reinforced composites $[4,5]$. Multiwalled nanocarbon tubes (MWNTs) have been widely used with different kinds of polymers for the development of high performance composite materials [6,7], however MWCNT/rubber nano-composites is still a evolving field and very little work has been documented on the subject.

Ethylene vinyl acetate (EVA) is widely used as an insulating and sheath material for high voltage cables and also in the footwear and toy industries due to its high flexibility and chemical inertness $[8,9]$. High-energy ionizing radiation has recently received a great deal of attention, primarily because of its ability to produce crosslinked networks with a wide range of polymers. The low operation cost, additive-free technique and room temperature operations are among the added advantages of radiation vulcanization over the existing vulcanizing techniques [10-14]. The modification and processing of particulate filled EVA using high energy radiation has been widely practiced, however not significant work has been reported on radiation induced effects on EVA reinforced with nanomaterials [15-17]. The nano-composites of EVA with MWNT are of special interest because incorporation of suitable amount of MWNT in EVA matrix is expected to 
significantly enhance its thermal and mechanical properties. However, high absorbed dose requirement for desired extent of crosslinking leads to cost enhancement as well as deterioration of mechanical properties of EVA at higher doses. Use of multifunctional acrylates (MFAs) and allylic reactive molecules during radiation processing have been proposed to overcome these drawbacks of radiation processing [18-21].

Radiation crosslinking i.e. gelation characteristic of filler reinforced polymer has been a subject of debate for various workers in the field [22, 23]. The objective of the present work was to analyze the effect of MWNT addition on the radiation induced crosslinking behavior of EVA-MWNT nano-composites. In addition to it, an attempt has also been made to look for suitable multifunctional acrylates for efficient radiation cross-linking of these nanocomposite blends.

\section{Materials and methods}

\subsection{Materials}

EVA in granular form was supplied by a local supplier (M/s Polystar Chemicals, Mumbai), MWNT powder from M/s Nanocyl, Belgium was used without further purification. Toluene and xylene used for studies were of AnalaR grade (Purity 99.9\%). The multifunctional acrylates were procured from Aldrich chemicals, USA and used as such without further purification.

\subsection{Sample preparation and characterization}

A series of nano-composites of EVA and MWNT was prepared by initially mixing the two components homogeneously on a Brabender Plasticorder from M/s Brabender, Germany at $130^{\circ} \mathrm{C}$ for $15 \mathrm{~min}$. The nano-composites compositions and sample designations have been represented in Table 1. The homogeneous mix was cut to small pieces and compressed into sheets of size $12 \times$ $12 \mathrm{~cm}$ of different thicknesses in range $1-4 \mathrm{~mm}$ using compression-molding machine at $1500 \mathrm{~N} / \mathrm{m}^{2}$ pressure for 2 minutes at $130^{\circ} \mathrm{C}$.

Irradiation was carried out under aerated condition in a gamma chamber 5000 (GC-5000) having Co-60 gamma source supplied by M/s BRIT India.
The dose rate of gamma chamber was ascertained to be $3.5 \mathrm{kGy} / \mathrm{hr}$ by using Fricke dosimetry prior to irradiation of samples.

For the sorption studies, radiation crosslinked blends were Soxhlet extracted at elevated temperature for 12 hours to extract any sol content using xylene as solvent. The insoluble gel part was then dried initially under room conditions and later in a dissector. The dried blend so obtained was cut into uniform square pieces $(1 \mathrm{~cm} \times 1 \mathrm{~cm})$ using a sharp edged die and used for swelling studies. Preweighed samples were placed in a 200-mesh stainless steel compartment and immersed in excess xylene. The swelled samples were periodically removed, blotted free of surface xylene using laboratory tissue paper, weighed on AND analytical balance (accuracy $0.00001 \mathrm{~g}$ ) in stopper bottles and returned to the swelling medium. Measurements were taken until the samples reached constant weight.

Hardness was measured in accordance with ASTM D2240 using durometer (M/s Asha-testers, Bluesteel Eng. (P) Ltd, India). The units of hardness were expressed in shore A. The density (in $\mathrm{g} \cdot \mathrm{cm}^{-3}$ ) was determined by using density balance from $\mathrm{M} / \mathrm{s}$ AND (accuracy $0.00001 \mathrm{~g}$ ) using suitable liquids.

The gel content was determined by refluxing the samples with xylene for $12 \mathrm{hrs}$. The insoluble portion obtained was rinsed with methanol and dried in vacuum oven at $60^{\circ} \mathrm{C}$ to a constant weight. Gel content was evaluated using following relationship (Equation 1):

Gel content $=\left(\frac{W_{g}}{W_{i}}\right)$

where $W_{g}$ and $W_{i}$ are the weight of insoluble fraction and initial weight respectively.

\section{Results and discussion}

\subsection{Scanning electron microscopy}

The scanning electron micrographs of fractured surfaces have been shown in Figure 1. It is clear that for all compositions EVA-MWNT were well mixed as no agglomeration of nanotubes was observed in the composition range studied. 

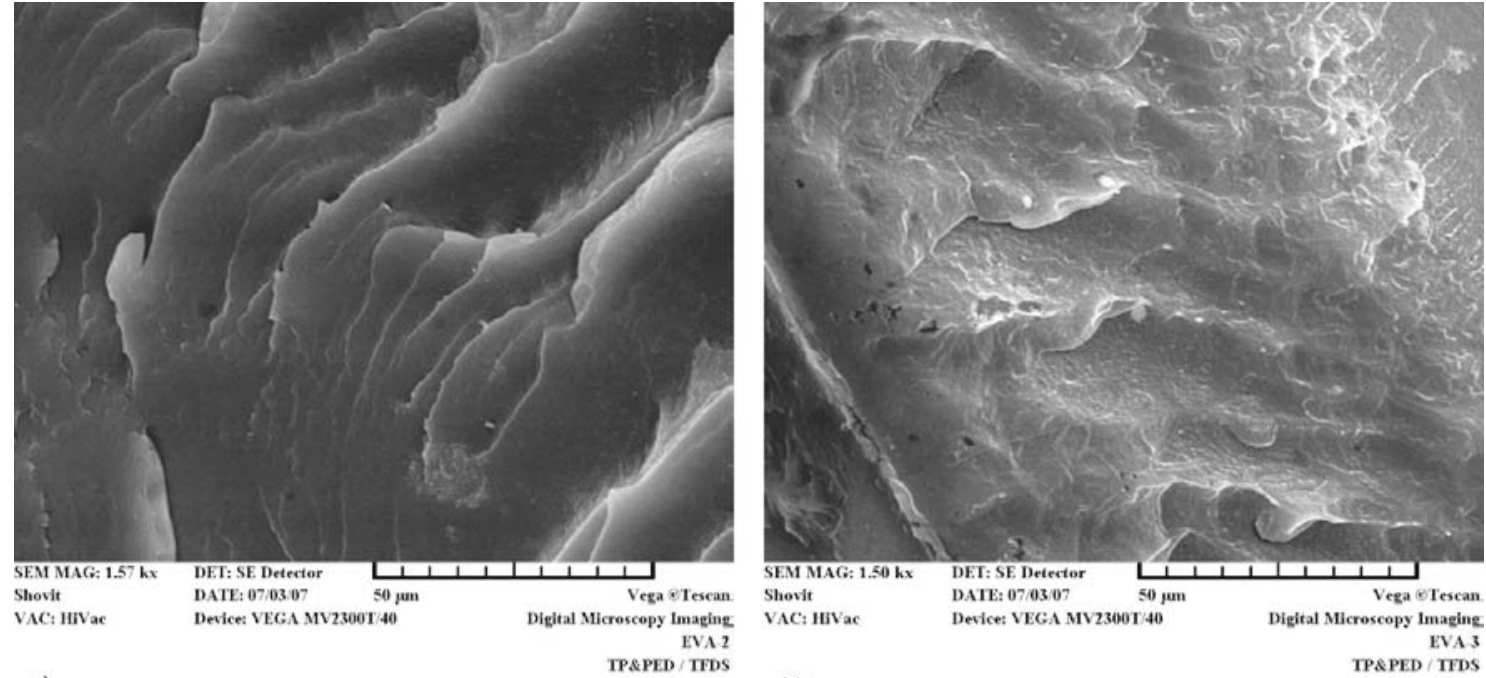

a)
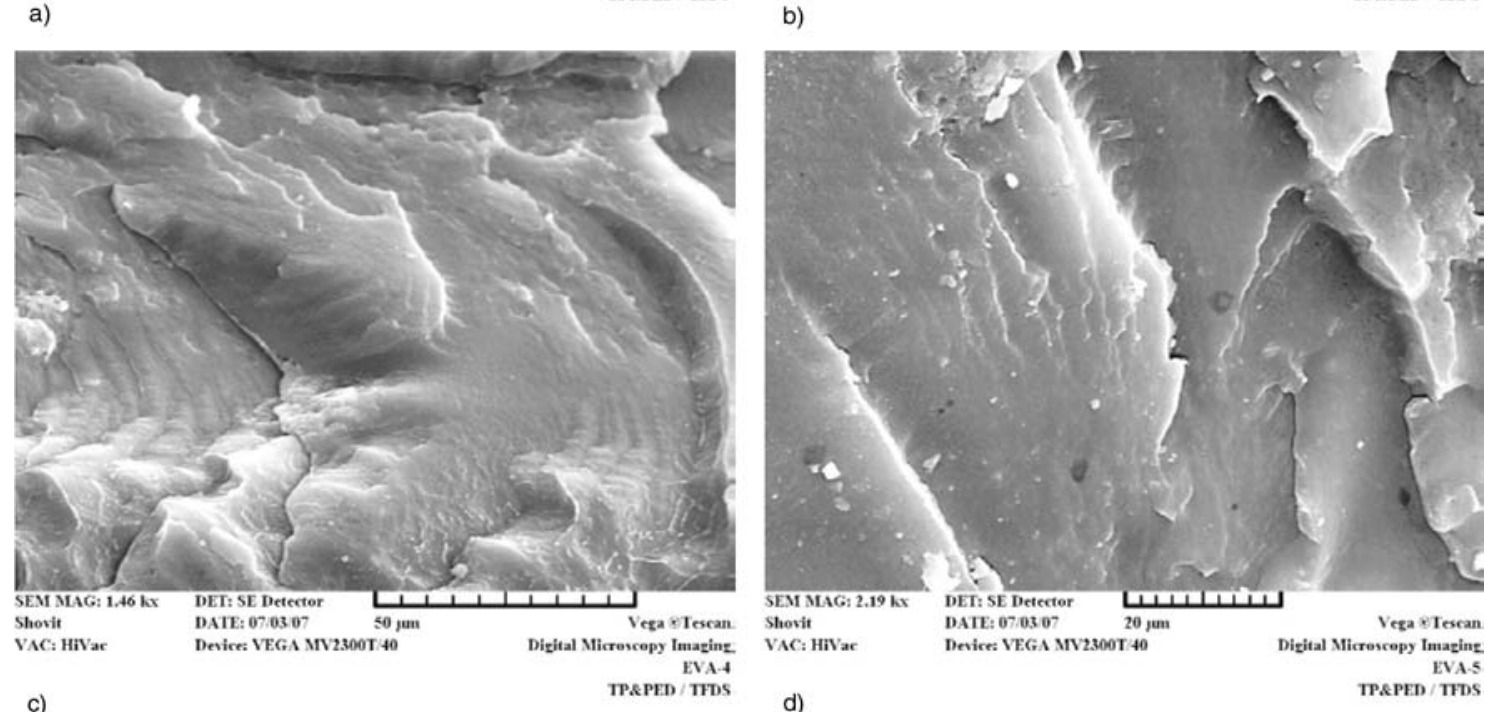

Figure 1. Scanning electron micrographs of EVA-MWNT nano-composites a) $2 \%$ MWNT, b) $3 \%$ WNT, c) $4 \%$ MWNT, d) $5 \% \mathrm{MWNT}$

\subsection{Effect of gamma radiation on nano-composites}

Figure 2 shows the change in the gel content of EVA-MWNTs nano-composites on irradiation. Un-irradiated samples were easily soluble in hot xylene, however nano-composites irradiated to a dose $>50 \mathrm{kGy}$ were partly soluble due to the formation of a three-dimensional network.

In order to quantitatively evaluate crosslinking and chain scission yields of irradiated EVA-MWNT nano-composites, plots of $S+S^{1 / 2}$ vs. 1/absorbed dose from the Charlesby-Pinner equation (Equation 2) for the different blend compositions were drawn (Figure 3) [24-25]:

$S+\sqrt{S}=\frac{p_{0}}{q_{0}}+\frac{1}{\alpha P_{n} D}$

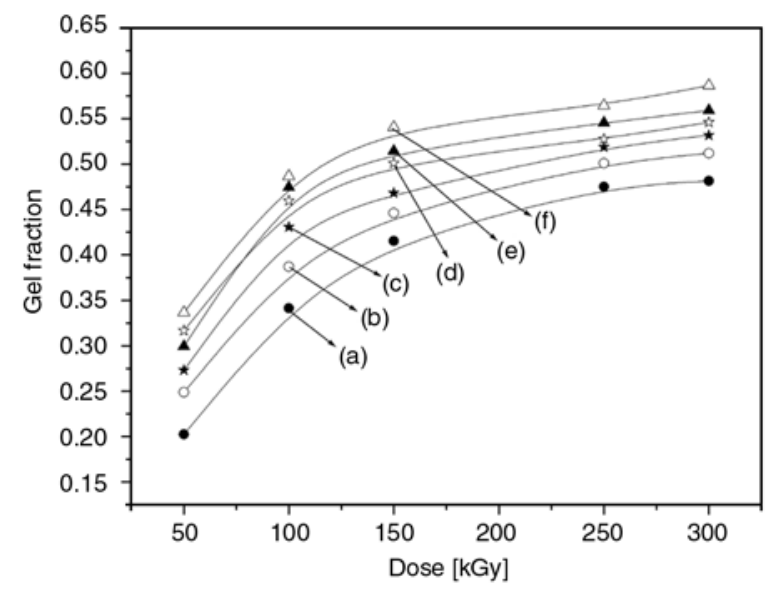

Figure 2. Gel fraction of EVA-MWNT nano-composites on irradiation at a dose rate of $5 \mathrm{kGy} \cdot \mathrm{h}^{-1}$ a) $\mathrm{EV}_{\mathrm{NT} 00}$, b) $\mathrm{EV}_{\mathrm{NT} 05}$, c) $\mathrm{EV}_{\mathrm{NT} 1}$, d) $\mathrm{EV}_{\mathrm{NT} 2}$, e) $\left.\mathrm{EV}_{\mathrm{NT} 3}, \mathrm{f}\right) \mathrm{EV}_{\mathrm{NT5}}$ 


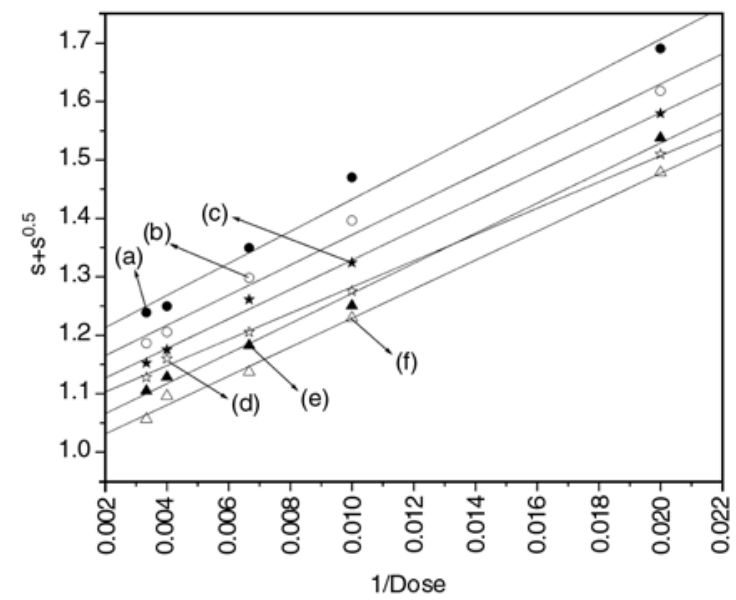

Figure 3. Charlesby-Pinner plot for EVA-MWNT nanocomposites a) $\mathrm{EV}_{\mathrm{NT} 00}$, b) $\mathrm{EV}_{\mathrm{NT} 05}$, c) $\mathrm{EV}_{\mathrm{NT} 1}$, d) EVNT2, e) $\mathrm{EV}_{\mathrm{NT} 3}$, f) $\mathrm{EV}_{\mathrm{NT}}$

Table 1. Compositional characteristics, designation and $p_{0} / q_{0}$ for nano-composite blends

\begin{tabular}{|c|c|c|}
\hline MWNT [\%] & Sample designation & $\mathbf{p}_{\mathbf{0}} / \mathbf{q}_{\mathbf{0}}$ \\
\hline 00 & $\mathrm{EV}_{\mathrm{NT} 00}$ & 1.16 \\
\hline 0.5 & $\mathrm{EV}_{\mathrm{NT} 05}$ & 1.11 \\
\hline 1.0 & $\mathrm{EV}_{\mathrm{NT} 1}$ & 1.08 \\
\hline 2.0 & $\mathrm{EV}_{\mathrm{NT} 2}$ & 1.06 \\
\hline 3.0 & $\mathrm{EV}_{\mathrm{NT} 3}$ & 1.01 \\
\hline 5.0 & $\mathrm{EV}_{\mathrm{NT} 5}$ & 0.98 \\
\hline
\end{tabular}

where $S$ is the sol fraction, $P_{n}$ the number averaged degree of polymerization, $D$ radiation dose, $p_{0}$ and $q_{0}$ are fraction of ruptured and crosslinked mainchain units per unit dose (proportional to the radiation chemical yields of degradation and crosslinking).

From Table 1 and Figure 3 it is clear that $\mathrm{EV}_{\text {NT5 }}$ is most efficiently crosslinked on irradiation and the crosslinking extent increases almost linearly with MWNT content in the nano-composite. Lower values of $p_{0} / q_{0}$ for higher MWNT content are suggestive of relatively improved radical-radical interactions in polymer nano-composites probably due to decrease in free-volume as reported by other workers for similar systems $[22,23,26]$.

\subsection{Crosslinking density of radiation processed nano-composites}

In order to gain further insight into radiation crosslinking of the EVA-MWNT nano-composites, crosslinking density measurements were carried out. The key parameters determining the amount of solvent absorbed at equilibrium swelling by a crosslinked network are the crosslink density and the extent of polymer-solvent interaction which is reported as the value of Flory-Huggins parameter $\chi$ $[27,28]$. The diffusion into solid samples depends on the availability of appropriate molecular size holes in the network, however the kinetic response which includes solvent sorption rate, the rate of approach to equilibrium and the transport mechanism controlling the solvent sorption may also depend upon additional factors like history of the samples and their composition $[28,29]$. The molecular weight between cross-links $\left(M_{c}\right)$ was estimated using the following relation, based on the theory initially proposed by Flory and Rehner (Equation 3) [30]:

$$
\bar{M}_{c}=-V_{1} \rho_{p} \frac{\phi_{p}^{1 / 3}-\phi_{p}^{1 / 2}}{\ln \left(1-\phi_{p}\right)+\phi_{p}+\chi \phi_{p}^{2}}
$$

where, V1 is the molar volume of the solvent, $\rho_{p}$ is the polymer density, $\phi_{p}$ is the volume fraction of the polymer in the swollen matrix and $\chi$ is the Flory-Huggins interaction parameter between solvent and polymer which can be calculated using Equation (4):

$\chi=\beta+\frac{V_{1}}{R T}\left(\delta_{s}-\delta_{p}\right)^{2}$

where $\delta_{\mathrm{s}}$ and $\delta_{p}$ are the solubility parameters of the solvent and the polymer, $\beta$ is the lattice constant whose value is taken as $0.34, R$ is the universal gas constant and $T$ is absolute temperature. The variation in crosslinking density with absorbed dose for nano-composites is plotted in Figure 4. It is clear from the figure that though at lower doses there is not much difference among the crosslink densities of different nano-composites but the difference is significant at higher absorbed doses. This observation reflects the higher radiation sensitivity of nano-composites with higher MWNT fraction. The inferences from the $p_{0} / q_{0}$ values, from sol-gel analysis give an idea of the predominant process (crosslinking/degradation) which the polymer undergoes in the dose range of study. The crosslinking density measurements on the other hand indicate that even if all samples predominantly undergo same process (crosslinking in this study) which among them is more prone to crosslinking at a given dose. 


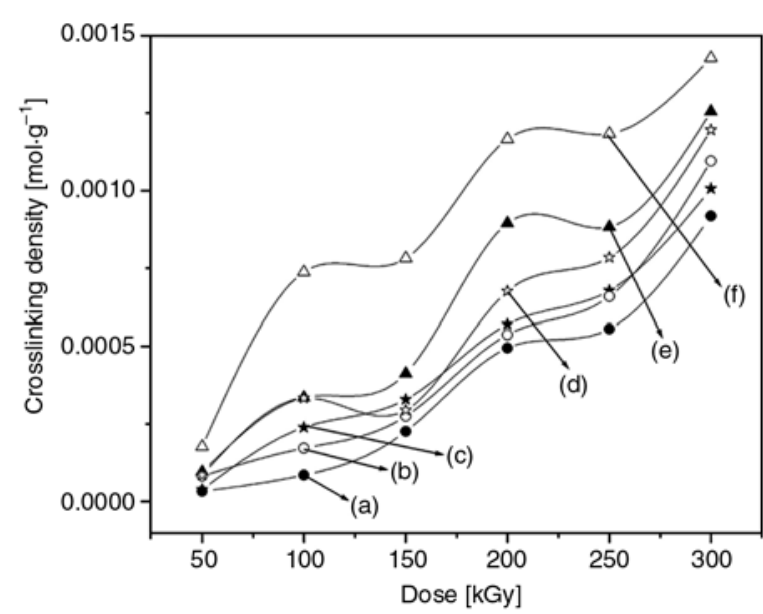

Figure 4. Crosslinking density of EVA-MWNT nanocomposites on irradiation at a dose rate of $5 \mathrm{kGy} \cdot \mathrm{h}^{-1}$ a) $\mathrm{EV}_{\mathrm{NT} 00}$, b) $\mathrm{EV}_{\mathrm{NT} 05}$, c) $\mathrm{EV}_{\mathrm{NT} 1}$, d) $\mathrm{EV}_{\mathrm{NT} 2}$, e) $\left.\mathrm{EV}_{\mathrm{NT} 3}, \mathrm{f}\right) \mathrm{EV}_{\mathrm{NT} 5}$

It is thus not improbable that the gel content attains a plateau value whereas, crosslinking density keeps increasing due to further increase in intermolecular radical-radical combinations and other rearrangements. Nevertheless, crosslinking density values followed the order $\mathrm{EV}_{\mathrm{NT} 5}>\mathrm{EV}_{\mathrm{NT} 3}>\mathrm{EV}_{\mathrm{NT} 2}>\mathrm{EV}_{\mathrm{NT} 1}>$ $\mathrm{EV}_{\mathrm{NT} 05}>\mathrm{EV}_{\mathrm{NT} T 00}$, in the complete dose range studied indicating predominantly crosslinking behavior of nano-composites on irradiation and enhancement in the crosslinking density with the incorporation of MWNT.

In general, additives are expected to induce a diminishing effect of radiation, as part of energy deposited during irradiation is expected to be absorbed by additives in addition to the bulk matrix. Furthermore, fillers may scavenge the radicals generated on the polymer matrix this may hinder the radical-radical interactions and hence reduce overall crosslinking density and gel fraction. Studies have shown that rate of radiation induced polymerization decreases in presence of inorganic fillers though the kinetics remains unchanged $[22,23,26]$.

Nanoparticulate fillers like carbon nanotubes, if distributed uniformly, are expected to sit in the available free volume of the matrix, also the concentration of MWNTs in the study is too small to directly contribute to significant absorption of energy. Thus, the enhancement in the crosslinking yield after the MWNT incorporation indicates the formation of multi ionization spurs yielding Y-crosslinking and also increased possibility of spur overlap due to reduced free volume. It can therefore be safely said that neutralization of single ionization spurs, with increase in MWNT, is not significant in the present system as reported earlier $[31,32]$.

\subsection{Density of the nano-composites}

The density of nano-composites is expected to change after irradiation because of the change in free-volume associated with radiation induced crosslinking or degradation. Densities of the EVAMWNT nano-composite were found to increase marginally with the radiations dose and with MWNT fraction except that with highest content of MWNT as shown in Figure 5. This behavior can be explained on the basis of free volume theory; the increase in crosslinking with increase in absorbed dose for the samples with higher content of MWNT decreases the free volume due to strong interfacial interaction between EVA and nanotube surfaces, and thus increases the density, on the other hand, irradiation of EVA with lower MWNT content leads to increase in density but not to that extent as it still has free volume due to lower concentration of MWNT [33]. The samples did not show any significant increase in density after certain absorbed doses clearly, indicating that increase in crosslink density of samples does not contribute to decrease in free volume after certain extent of crosslinking.

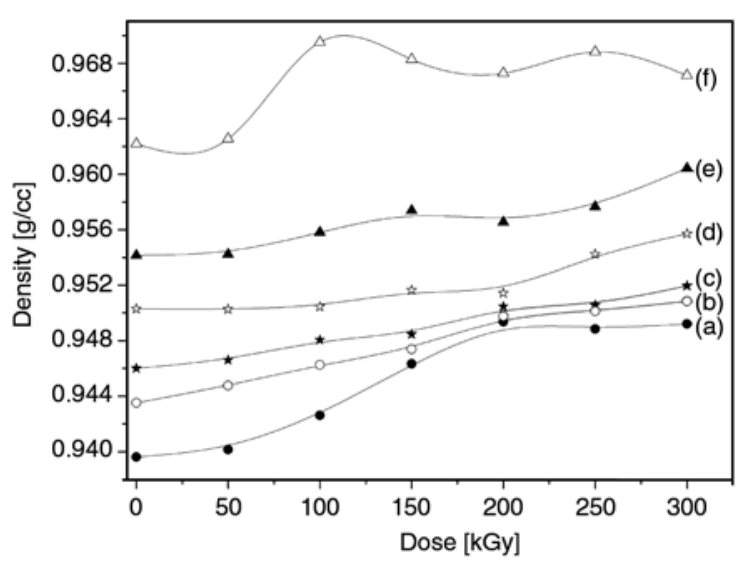

Figure 5. Density of EVA-MWNT nano-composites on irradiation at a dose rate of $5 \mathrm{kGy} \cdot \mathrm{h}^{-1}$ a) $\mathrm{EV}_{\mathrm{NT} 00}$, b) $\mathrm{EV}_{\mathrm{NT} 05}$, c) $\mathrm{EV}_{\mathrm{NT} 1}$, d) $\mathrm{EV}_{\mathrm{NT} 2}$, e) $\mathrm{EV}_{\mathrm{NT} 3}$, f) $\mathrm{EV}_{\mathrm{NT} 5}$

\subsection{Hardness}

Figure 6 shows the compositional dependence of hardness of the samples with increase in radiation dose. It was found that initially the hardness of the 


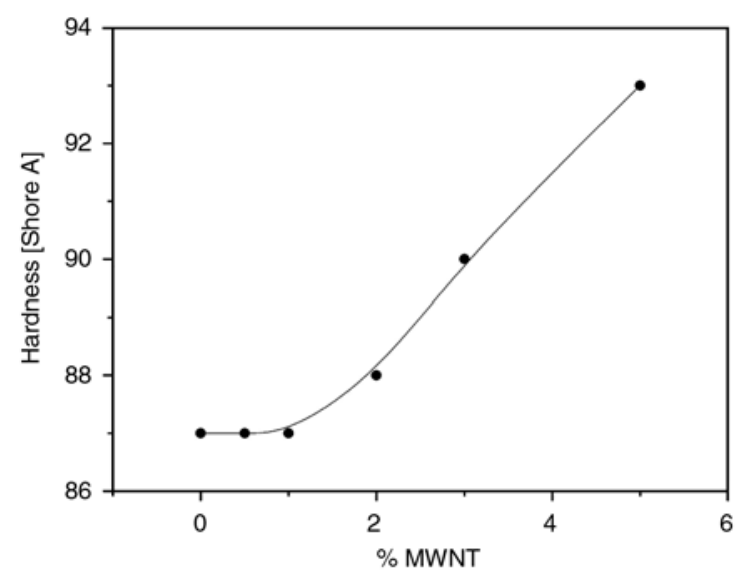

Figure 6. Variation of shore A hardness of EVA-MWNT nano-composites

EVA-MWNT nano-composites increases sharply for $>1 \%$ MWNT loading. By definition, hardness is generally referred to the resistance of material to the local deformation, and the results proved that the EVA-MWNT nano-composites, with higher nanotube content, are more resistant towards local deformations. Though radiation-induced crosslinking in polymeric systems is expected to increase the hardness of the samples linearly on irradiation, the hardness values of irradiated EVA-MWNT nanocomposites did show this trend only after a threshold amount of MWNT was incorporated in the nano-composites indicating MWNT content and not the absorbed dose was predominant reason for increase in hardness for these nanocomposites.

\subsection{Radiation sensitivity of EVA-MWNT nano-composites in presence of MFAs}

The studies in earlier sections indicated that gel content of the nano-composites varied in the range $0.25-0.55$ depending on the radiation dose. Multifunctional acrylates (MFAs) are generally used for lowering the absorbed dose requirement [18-20]. The Table 2 provides the details of acrylates used for the study and Figure 7 and 8 depicts the variation in gel content on incorporation of two TMPTA and TMPTMA in EVA-MWNT composites.

It is evident from the figures that the nano-composites are more efficiently crosslinked after incorporation of MFAs. The improvement in the radiation sensitivity of the nano-composite after MFA addition was further established by crosslinking density measurements of nano-composites crosslinked using MFAs as shown in Figure 9 and 10.

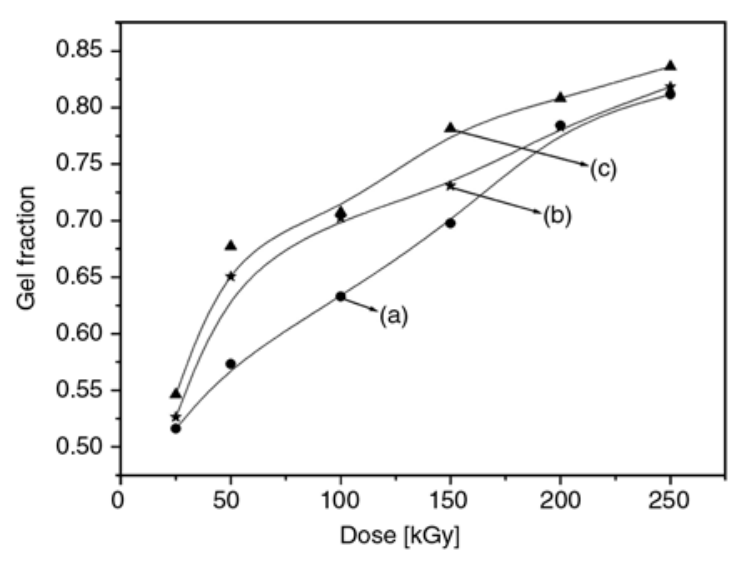

Figure 7. Gel fractions of EVA-MWNT nano-composites containing TMPTA (3\%) on irradiation at a dose rate of $5 \mathrm{kGy} \cdot \mathrm{h}^{-1}$ a) $\mathrm{EV}_{\mathrm{NT} 00^{\mathrm{TM}}}$, b) $\mathrm{EV}_{\mathrm{NT} 1}{ }^{\mathrm{TM}}$, c) $\mathrm{EV}_{\mathrm{NT} 3}{ }^{\mathrm{TM}}$

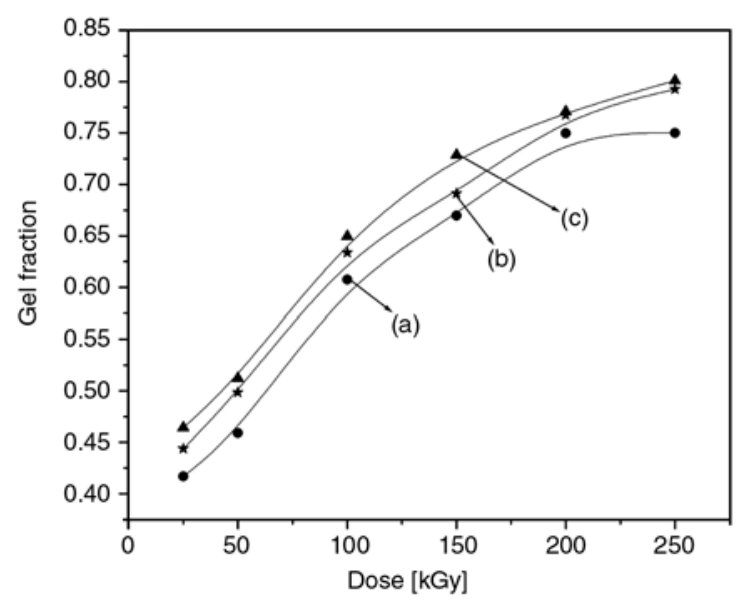

Figure 8. Gel fraction of EVA-MWNT nano-composites containing TMPTMA (3\%), on irradiation at a dose rate of $5 \mathrm{kGy} \cdot \mathrm{h}^{-1}\left(\mathrm{EVV}_{\mathrm{NT} 00^{\mathrm{TMM}}}{ }^{\mathrm{TM}}\right.$ b) $\mathrm{EV}_{\mathrm{NT} 1}{ }^{\mathrm{TMM}}$, c) $\mathrm{EV}_{\mathrm{NT} 3}{ }^{\mathrm{TMM}}$

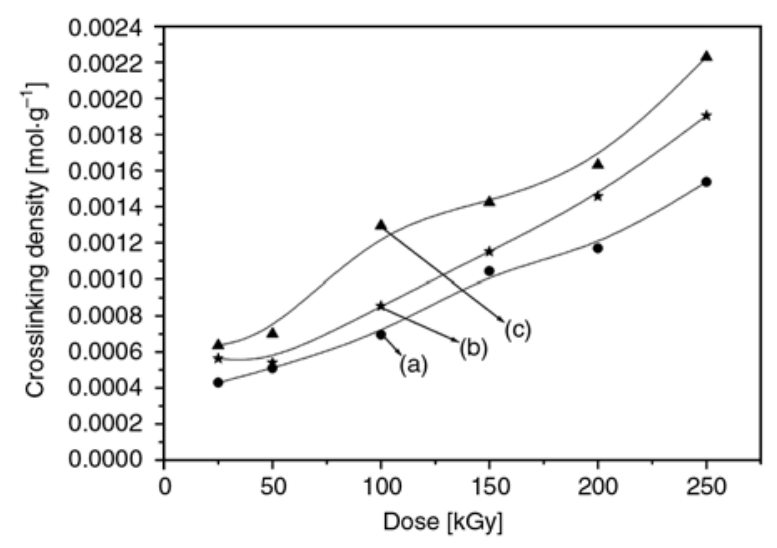

Figure 9. Crosslinking density of EVA-MWNT nanocomposites containing TMPTA (3\%), on irradiation at a dose rate of $5 \mathrm{kGy} \cdot \mathrm{h}^{-1}$ a) $\mathrm{EV}_{\mathrm{NT} 00}{ }^{\mathrm{TM}}$, b) $\mathrm{EV}_{\mathrm{NT} 1}^{\mathrm{TM}}$, c) $\mathrm{EV}_{\mathrm{NT} 3}{ }^{\mathrm{TM}}$

Increase in the gel content on introduction of MFAs in the pure nano-composites was obviously due to 
Table 2. Properties of multifunctional acrylates used in the study

\begin{tabular}{|l|c|c|c|c|}
\hline \multicolumn{1}{|c|}{ Multi functional acrylate (MFA) } & Structure & Functionality & M.W. & Designation \\
\hline Blank & - & Nil & - & EV \\
\hline Trimethylolpropane triacrylate (TMPTA) & $\left(\mathrm{H}_{2} \mathrm{C}=\mathrm{CHCO}_{2} \mathrm{CH}_{2}\right)_{3} \mathrm{CC}_{2} \mathrm{H}_{5}$ & 3 & 296.32 & EV \\
\hline Trimethylolpropane trimethacrylate (TMPTMA) & {$\left[\mathrm{H}_{2} \mathrm{C}=\mathrm{C}_{2}\left(\mathrm{CH}_{3}\right) \mathrm{CO}_{2} \mathrm{CH}_{2}\right]_{3} \mathrm{CC}_{2} \mathrm{H}_{5}$} & 3 & 338.40 & EV \\
\hline
\end{tabular}

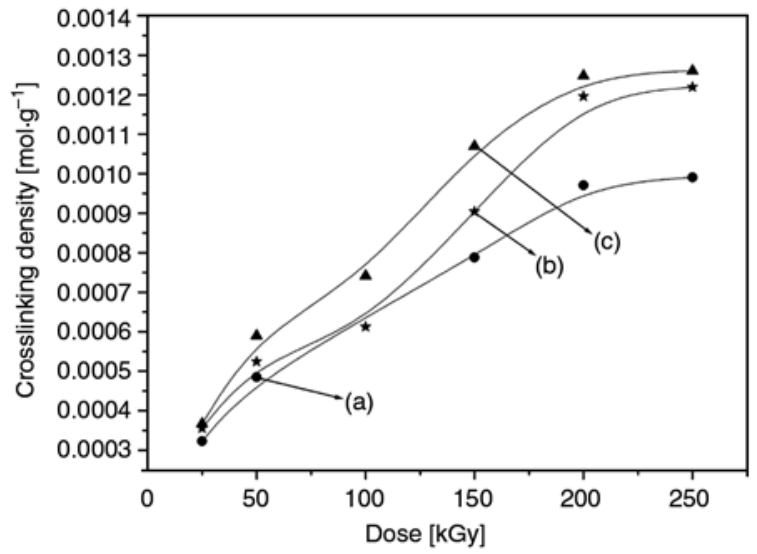

Figure 10. Crosslinking density of EVA-MWNT nanocomposites containing TMPTMA (3\%), on irradiation at a dose rate of $5 \mathrm{kGy} \cdot \mathrm{h}^{-1}$ a) $\mathrm{EV}_{\mathrm{NT} 00}{ }^{\mathrm{TMM}}$, b) $\mathrm{EV}_{\mathrm{NT} 1}{ }^{\mathrm{TMM}}$, c) $\mathrm{EV}_{\mathrm{NT}}{ }^{\mathrm{TMM}}$

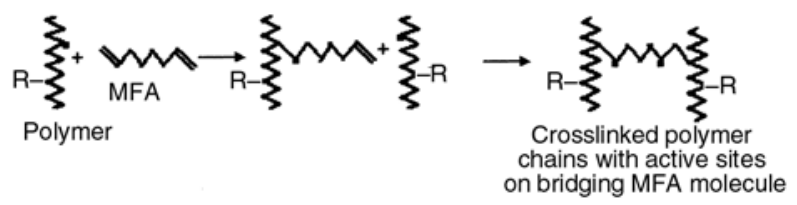

Figure 11. Scheme of the effect of multifunctional acrylates (MFA) on the corsslinking process

multifunctional acrylates employed in this study, as they are known to efficiently form bridges between the radicals generated on two different polymer chains causing inter molecular crosslinking thereby contributing to increased gel fraction as shown in Figure 11 [10-13].

In accordance with Figure 11 the crosslinking efficiency of a MFA is expected to be a function of its extent of unsaturation (functionality) and its compatibility with the polymer matrix. Since, the acrylates employed in the study were of same functionality, it was interesting to observe that radiation sensitivity of acrylate was much higher than methacrylate. This may due to better compatibility of acrylate in comparison to methacrylate with that of matrix being crosslinked using these MFAs. The compatibility of MFA with a polymer blend can be adequately judged by its swelling behavior in that MFA. The MFA uptake per $100 \mathrm{~g}$ of rubber blend has been represented in Figure 12, higher swelling

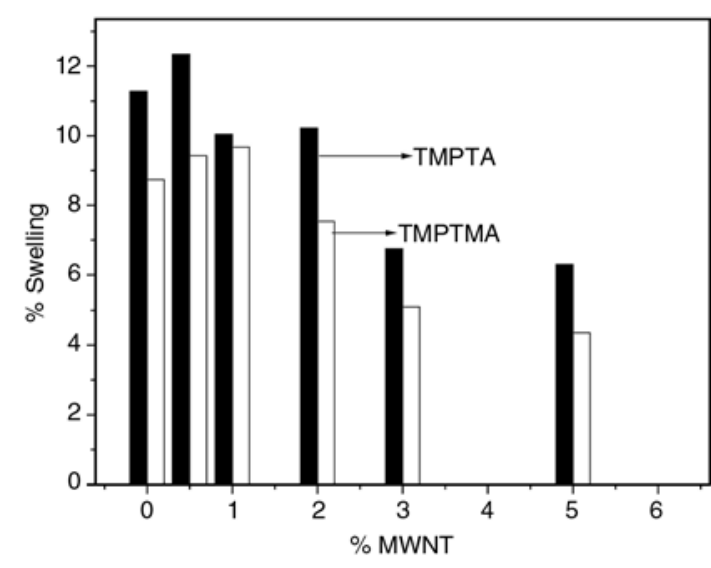

Figure 12. Multifunctional acrylate uptake by EVAMWNT nano-composites

indicating similarity in cohesive energy densities of the two and better interaction between TMPTA molecules and nano-composite.

However, penetration of MFA molecules was found to decrease with increase in MWNT loading. Furthermore, the higher efficiency of the TMPTA over TMPTMA, in addition to above mentioned better interaction of TMPTA with nano-composite matrix, can be explained on the basis of the polymerization kinetics of acrylate and methacrylate monomers. Rate constants for propagation reported in the literature for methacrylates are almost two orders of magnitude lower than those of acrylates. A comparison between rate constant for propagation values and average termination rate constant values for some acrylates and methacrylates is given in Table 3. Due to low $\mathrm{kp}$ values of methacrylates as compared to the acrylates the crosslinking reaction with methacrylates (radical recombination) is expected to be less efficient.

\section{Conclusions}

Gel fraction, crosslinking density measurements and Charleby-Pinner parameter for the different compositions of EVA-MWNT nano-composites indicated higher radiation sensitivity of the nanocomposite matrix with higher MWNT concentration. This was attributed to the enhanced probabil- 
Table 3. Literature value for the rate parameters

\begin{tabular}{|c|c|c|c|c|c|c|c|c|}
\hline Monomer & 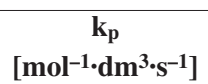 & Solvent & $\begin{array}{c}\mathbf{T} \\
{\left[{ }^{\circ} \mathbf{C}\right]}\end{array}$ & Reference & $\begin{array}{c}<2 \mathrm{k}_{\mathrm{t}}> \\
{\left[\mathrm{mol}^{-1} \cdot \mathrm{dm}^{3} \cdot \mathrm{s}^{-1}\right]}\end{array}$ & Solvent & $\begin{array}{c}\mathbf{T} \\
{\left[{ }^{\circ} \mathbf{C}\right]}\end{array}$ & Reference \\
\hline BA & 1800 & Bulk & 30 & $\begin{array}{l}{ }^{31} \text { Van Herk } \\
(2000)\end{array}$ & $(1.2-6) \cdot 10^{8}$ & Bulk & 30 & $\begin{array}{l}{ }^{33} \text { Beuerman et } \\
\text { al. } 1996\end{array}$ \\
\hline BMA & 370 & Bulk & 25 & $\begin{array}{l}{ }^{31} \text { Van Herk } \\
(2000)\end{array}$ & $(0.1-3) \cdot 10^{8}$ & $\mathrm{CH}$ & 22 & $\begin{array}{l}\text { 34Takacs et al. } \\
2002\end{array}$ \\
\hline MA & 13300 & Bulk & 25 & $\begin{array}{l}{ }^{31} \text { Van Herk } \\
(2000)\end{array}$ & $(0.5-18) \cdot 10^{8}$ & $\mathrm{CH}$ & 22 & $\begin{array}{l}{ }^{34} \text { Takacs et al. } \\
2002\end{array}$ \\
\hline MMA & 323 & Bulk & 25 & $\begin{array}{l}{ }^{31} \text { Van Herk } \\
(2000)\end{array}$ & $6 \cdot 10^{7}$ & Bulk & 22 & $\begin{array}{l}{ }^{33} \text { Beuerman et } \\
\text { al. } 1996\end{array}$ \\
\hline $\mathrm{CHA}$ & 2722 & Benzene & 30 & $\begin{array}{l}{ }^{32} \text { Brandrup et al. } \\
\text { (1999) }\end{array}$ & $(0.1-4) \cdot 10^{8}$ & $\mathrm{CH}$ & 22 & $\begin{array}{l}\text { 34Takacs et al. } \\
2002\end{array}$ \\
\hline CHMA & 601 & Bulk & 25 & $\begin{array}{l}\text { 31Van Herk } \\
(2000)\end{array}$ & $(4.30-7.1) \cdot 10^{8}$ & $\mathrm{CH}$ & 22 & $\begin{array}{l}\text { 34Takacs et al. } \\
2002\end{array}$ \\
\hline
\end{tabular}

$k_{p}$-rate constant for propagation, $<2 k_{t}>$-average termination rate constant; BA-Butyl acrylate; BMA-Butyl methacrylate; MA-Methylacrylate; MMA-Methyl methacrylate; CHA-Cyclohexyl acrylate; CHMA-cyclohexyl methacrylate; CH-Cyclo hexane

ity of spur overlap, due to the reduction in the free volume of the nano-composite matrix with higher MWNT content. The incorporation of MWNT also results in the increased hardness and higher density of the nano-composite matrix. A significant reduction in the dose requirement was achieved with incorporation of multifunctional acrylates and the results established lower efficiency of trimethylolpropane trimethacrylate than trimethylolpropane triacrylate in radiation induced crosslinking process.

\section{References}

[1] Beaucage G., Rane S., Schaefer D. W., Lonf G., Fisher D.: Morphology of polyethylene-carbon black composites. Journal of Polymer Science Part B: Polymer Physics, 37, 1105-1119 (1999).

DOI: 10.1002/(SICI)1099-0488(19990601)37:11 $\leq 1105:$ :AID-POLB6>3.0.CO;2-5

[2] Li Z. H., Zhang J., Chen S. J.: Effects of carbon blacks with various structures on vulcanization and reinforcement of filled ethylene-propylene-diene rubber. Express Polymer Letters, 2, 695-704 (2008). DOI: $10.3144 /$ expresspolymlett.2008.83

[3] Qian D., Dickey E. C., Andrews R., Rantell T.: Load transfer and deformation mechanisms in carbon nanotube-polystyrene composites. Applied Physics Letters, 76, 2868-2870 (2000).

DOI: $10.1063 / 1.126500$

[4] Oya A.: Polypropylene clay nanocomposites. in 'Polymer nano-composites' (eds.: Pinnavaia T. J., Beall G. W.) Wiley, London, 151-172. (2000).
[5] Giannelis E. P., Krishnamoorti R., Manias E.: Polymer-silicate nanocomposites: Model systems for confined polymers and polymer brushes. Advances in Polymer Science, 138, 107-148 (1998).

DOI: $10.1007 / 3-540-69711-X \quad 3$

[6] Romhány G., Szebényi, G.: Interlaminar crack propagation in MWCNT/fiber reinforced hybrid composites. Express Polymer Letters, 3, 145-151 (2009). DOI: $10.3144 /$ expresspolymlett.2009.19

[7] Ajayan P. M., Stephan O., Colliex C., Trauth D.: Aligned carbon nanotube arrays formed by cutting a polymer resin-nanotube composite. Science, 265, 1212-1214 (1994). DOI: $10.1126 /$ science.265.5176.1212

[8] Schadler L. S., Giannaris S. C., Ajayan P. M.: Load transfer in carbon nanotube epoxy composites. Applied Physics Letters, 73, 3842-3847 (1998). DOI: $\underline{10.1063 / 1.122911}$

[9] Placek V., Bartonicek B., Hnát V., Otáhal B.: Dose rate effects in radiation degradation of polymer-based cable materials. Nuclear Instruments and Methods in Physics Research Section B: Beam Interactions with Materials and Atoms, 208, 448-453 (2003). DOI: $10.1016 / \mathrm{S} 0168-583 \mathrm{X}(03) 00626-8$

[10] Aoshuang Y., Zhengtao G., Li L., Ying Z., Peng Z.: Mechanical properties of radiation vulcanized NR/BR blending system. Radiation Physics and Chemistry, 63, 497-500 (2002). DOI: $10.1016 / \mathrm{S} 0969-806 \mathrm{X}(01) 00634-\mathrm{X}$

[11] Dubey K. A., Pujari P. K., Ramnani S. P., Kadam R. M., Sabharwal S.: Microstructural studies of electronbeam irradiated celluose pulp. Radiation Physics and Chemistry, 69, 395-400 (2004). DOI: $10.1016 /$ j.radphyschem.2003.07.005 
[12] Dubey K. A., Bhardwaj Y. K., Chaudhari C. V., Kumar V., Goel N. K., Sabharwal S.: Radiation processed polychloroprene-co-ethylene-propene diene terpolymer blends: Effect of radiation vulcanization on solvent transport kinetics. Nuclear Instruments and Methods in Physics Research Section B: Beam Interactions with Materials and Atoms, 276, 795-801 (2009).

DOI: $10.1016 /$ j.nimb.2008.12.008

[13] Chaudhari C. V., Bhardwaj Y. K., Patil N. D., Dubey K. A., Kumar V., Sabharwal S.: Radiation induced vulcanization of natural rubber latex in presence of styrene-butadiene rubber latex addition. Radiation Physics and Chemistry, 72, 613-618 (2005). DOI: $10.1016 /$ j.radphyschem.2004.03.012

[14] Dubey K. A., Bhardwaj Y. K., Chaudhari C. V., Sabharwal S.: Radiation processed styrene-butadiene-coethylene-propylene diene rubber blends: Compatibility and swelling studies. Journal of Applied Polymer Science, 99, 3638-3649 (2006).

DOI: $10.1002 / \mathrm{app} .22765$

[15] Zanetti M., Camino G., Thomann R., Müllhaupt R.: Synthesis and thermal behaviour of layered silicateEVA nanocomposites. Polymer, 42, 4501-4507 (2001).

DOI: $\underline{\text { 10.1016/S0032-3861(00)00775-8 }}$

[16] Lawandy S. N., Halim S. M., Darwish N. A.: Structure aggregation of carbon black in ethylene-propylene diene polymer. Express Polymer Letters, 3, 152-158 (2009).

DOI: $10.3144 /$ expresspolymlett.2009.20

[17] Zhang W., Chen D., Zhao Q., Fang Y.: Effects of different kinds of clay and different vinyl acetate content on the morphology and properties of EVA/clay nanocomposites. Polymer, 44, 7953-7961 (2003). DOI: 10.1016/j.polymer.2003.10.046

[18] Dubey K. A., Bhardwaj Y. K., Chaudhari C. V., Sabharwal S., Mohan H.: Structure-reactivity studies on crosslinking of tri(propylene glycol diacrylate) in aqueous solutions. Reactive and Functional Polymers, 67, 282-293 (2007).

DOI: 10.1016/j.reactfunctpolym.2007.01.001

[19] Dubey K. A., Bhardwaj Y. K., Chaudhari C. V., Bhattacharya S., Gupta S. K., Sabharwal S.: Radiation effects on SBR-EPDM blends: A correlation with blend morphology. Journal of Polymer Science Part B: Polymer Physics, 44, 1676-1689 (2006).

DOI: $10.1002 /$ polb. 20822

[20] Banik I., Dutta S. K., Chaki T. K., Bhowmick A. K.: Electron beam induced structural modification of a fluorocarbon elastomer in the presence of polyfunctional monomers. Polymer, 40, 447-458 (1999). DOI: $10.1016 / \mathrm{S} 0032-3861(98) 00244-4$
[21] Jayasuriya M. M., Makuuchi K., Yoshi F.: Radiation vulcanization of natural rubber latex using TMPTMA and PEA. European Polymer Journal, 37, 93-98 (2001).

DOI: $10.1016 / \mathrm{S} 0014-3057(00) 00091-4$

[22] Chiou B-S., Raghavan S. R., Khan S. A.: Effect of colloidal fillers on the cross-linking of a UV-curable polymer: Gel point rheology and the Winter-Chambon criterion. Macromolecules, 34, 4526-4533 (2001). DOI: $10.1021 / \mathrm{ma} 010281 \mathrm{a}$

[23] Sharifa J., Yunus W. M. Z. W., Dahlan K. Z. H. M., Ahmad M. H.: Preparation and properties of radiation crosslinked natural rubber/clay nanocomposites. Polymer Testing, 24, 211-217 (2005).

DOI: $\underline{10.1016 / j . p o l y m e r t e s t i n g .2004 .08 .008}$

[24] Chapiro A.: Radiation chemistry of polymeric systems. Wiley, New York (1962).

[25] Charlesby A.: Atomic radiation and polymers. Pergamon Press, Oxford (1960).

[26] Zagórski Z. P.: EB-crosslinking of elastomers, how does it compare withb radiation crosslinking of other polymers? Radiation Physics and Chemistry, 71, 261265 (2004).

DOI: 10.1016/j.radphyschem.2004.03.083

[27] Hildenbrand J. H., Scott R. L.: The solubility of nonelectrolytes. Reinhold, New York (1949).

[28] Flory P. J.: Principles of polymer chemistry. Cornell University Press, Ithaca (1953).

[29] Stern S. A., Frisch H. L.: The selective permeation of gases through polymers. Annual Review of Material Science, 11, 523-550 (1981).

DOI: 10.1146/annurev.ms.11.080181.002515

[30] Flory P. J., Rehner R. J.: Statistical mechanics of cross-linked polymer networks. II: Swelling. Journal of Chemical Physics, 11, 521-526 (1943). DOI: $10.1063 / 1.1723792$

[31] Zagórski Z. P.: Modification, degradation and stabilization of polymers in view of the classification of radiation spurs. Radiation Physics and Chemistry, 63, 9-19 (2002).

DOI: $\underline{\text { 10.1016/S0969-806X(01)00475-3 }}$

[32] Ghassemi Mahidasht G. R., Gal O., Shafi N., Sang M., Vaklllnejad O. F., Cashmi R.: Effect of trace fillers on radiation crosslinking of polyethylene. Radiation Physics and Chemistry, 25, 349-357 (1985). DOI: 10.1016/0146-5724(85)90282-1

[33] Beuerman S., Paquet Jr. D. A., McMinn J. H., Hutchinson R. A.: Determination of free-radical propagation rate coefficients of butyl, 2-ethylhexyl, and dodecyl acrylates by pulsed-laser polymerization. Macromolecules, 29, 4206-4215 (1996).

DOI: $10.1021 / \mathrm{ma960081 \textrm {c }}$

[34] Takács E., Emmi S. S., Wojnárovits L.: Study of polymerization kinetics of acrylic and methacrylic acid esters at low conversions. Radiation Physics and Chemistry, 55, 621-624 (1999). DOI: 10.1016/S0969-806X(99)00258-3 